\title{
Jovens em conflito com a lei: considerações sobre atos infracionais e violência no município de Pelotas-RS
}

\author{
Jóvenes en conflicto con la ley: consideraciones de actos infractores y \\ violencia en la ciudad de Pelotas-RS
}
Young people in conflict with the law: considerations about infractions and violence in the city of Pelotas-RS

\author{
Manoela Vieira Neutzling1 \\ Luana Costa Bidigaray ${ }^{2}$
}

\begin{abstract}
Resumo
Este trabalho tem como objetivo discutir a relação entre violência e atos infracionais praticados por jovens em conflito com a lei, em Pelotas/RS, a partir dos resultados de pesquisa de mestrado realizada no Programa de PósGraduação em Sociologia da Universidade Federal de Pelotas (PPGS/UFPel). A metodologia é qualitativa e utilizou entrevista semi-estruturada aplicada aos agentes institucionais do Sistema de Garantia de Direitos, observação direta das reuniões da Rede Socioeducação e análise da dados secundários do Plano de Atendimento Municipal Socioeducativo (PAMSE). O referencial teórico baseia-se na sociologia configuracional e relacional de Norbert Elias, em Tavares dos Santos (2009) e Rolim (2016) para discutir as noções de "conflitualidade", "violência difusa" e "sociabilidade violenta", como também num diálogo entre Pais (2003) e Andrade (2007) para discutir as noções de juventude. Percebeu-se mudança no "perfil" do ato infracional que muitas vezes é atribuída ao "perfil" dos jovens, pelos agentes do campo sócio-jurídico. Dentre as relações da violência e ato infracional, o tráfico de drogas é um dos elementos mais citados como influenciador do contexto violento em que os jovens estão inseridos, além da violação de direitos na infância e adolescência, da configuração familiar, baixa escolaridade e condição socioeconômica da família. As categorias vínculo, renda, escola e família colaboraram para compreender as dinâmicas relacionais entre violência e ato infracional. Embora o campo sóciojurídico aponte para um "perfil mais gravoso", percebeu-se que a mudança envolve o perfil da ação e não o perfil dos jovens.
\end{abstract}

Palavras-Chave: Adolescentes em conflito com a lei; Atos Infracionais; Violência

\section{Resumen}

Este trabajo tiene como objetivo discutir la relación entre violencia y delitos practicado por los jóvenes en conflicto con la ley, en Pelotas-RS, de los resultados de la investigación de maestría realizada no Programa de Postgrado en Sociología en la Universidad Federal de Pelotas (PPGS/UFPel). La metodología de investigación es cualitativo y utilizó una entrevista semiestructurada aplicado a los agentes institucionales de Sistema de aseguramiento de derechos, observación directa de las reuniones de la Red Socioeducativa y análisis de datos secundarios del Plan Municipal de Atención Socioeducativa. El marco teórico se basa en la sociología configuracional y relacional por Norbert Elias, Tavares dos Santos (2009) y Rolim (2016) para discutir las nociones de "conflicto", "violencia difusa" y "sociabilidad violenta". Cambio notable en el "perfil" del delito que a menudo se atribuye al "perfil" de los jóvenes, por agentes del campo sociolegal. Entre las relaciones de violencia y delito, el narcotráfico es uno de los elementos más citados que influyen en el contexto violento en el que se insertan los jóvenes, más allá de la violación de los derechos en la infancia y adolescencia, del entorno familiar, baja educación y estatus socioeconómico familiar, Las categorías de bonos, ingresos, escuela y familia colaborar para comprender la dinámica relacional entre violencia e infracción. Aunque el campo sociolegal

\footnotetext{
${ }^{1}$ Mestre em Sociologia; Universidade Federal de Pelotas - UFPel; Pelotas, Rio Grande do Sul, Brasil; manoelaneutzling@gmail.com

${ }^{2}$ Mestre em Sociologia; Universidade Federal de Pelotas - UFPel, Pelotas, Rio Grande do Sul, Brasil; luanacbidigaray@gmail.com
} 
aponte para um "perfil más violento", se notó que el cambio involucra el perfil de la acción y no el perfil de los jóvenes.

Palabras claves: Adolescentes en conflicto con la ley, Delitos, Violencia

\begin{abstract}
This paper aims to discuss the relationship between violence and offenses committed by young people in conflict with the law, in Pelotas / RS, from the search results of Masters Degree in the Postgraduate Program in Sociology of the Federal University of Pelotas (PPGS / UFPel). The methodology is qualitative and used semi structured interview applied to the institutional agents of the Rights Guarantee System, direct observation of the meetings of the Socio-education and secondary data analysis of the Municipal Socio-Educational Service Plan (PAMSE). The theoretical framework is based on Norbert Elias's configurational and relational sociology, in Tavares dos Santos (2009) and Rolim (2016) to discuss the notions of "conflict", "violence diffuse "and" violent sociability", as well as in a dialogue between Pais (2003) and Andrade (2007) to discuss the notions of youth. There was a change in the "profile" of the offense that often is attributed to the "profile" of young people by agents of the socio-legal field. Among the relationships of violence and offense, drug trafficking is one of the most cited elements as influencing the violent context in which young people are inserted, as well as the violation of rights in childhood and adolescence, family configuration, low education and family socioeconomic status. At bond, income, school and family categories collaborate to understand the relational dynamics between violence and infringement. Although the socio-legal field points to a "more violent profile", It was noticed that change involves the profile of the action and not the profile of the young.
\end{abstract}

Keywords: Teenagers in conflict with the law; offenses committed; Violence

\title{
1. Introdução
}

O presente artigo busca discutir a relação entre violência e atos infracionais praticados por jovens ${ }^{3}$ em conflito com a lei, em Pelotas-RS, a partir dos resultados de pesquisa de mestrado realizada no Programa de Pós-Graduação em Sociologia da Universidade Federal de Pelotas (PPGS/UFPel), no período de 2018-2019. A a discussão desenvolvida articula os resultados de duas questões primordias da dissertação, a saber: como os agentes institucionais do Sistema de Garantia de Direitos reconhecem os jovens em cumprimento de Medida Socioeducativa (MSE) e como reconhecem os atos infracionais por eles praticados e com o que estão relacionados, na perspectiva dos agentes que trabalham diretamente com este público juvenil em diferentes momentos, desde a apreensão e registro do boletim de ocorrência, perpassando audiência e instauração do processo até a execução da medida.

Neste sentido, faz-se necesário esclarecer que ao discutir a relação entre os atos infracionais e a violência no município, não se pretende neste momento fazer uma análise comparativa entre o número de crimes e atos infracionais, mas identificar, problematizar e

\footnotetext{
${ }^{3}$ Neste trabalho é considerado o termo adolescente, pois no Estatuto da Criança e do Adolescente está previsto o ato infracional e as medidas socioeducativas. Porém, para análise e discussão é utilizado o termo juventude como categoria sociológica.
} 
discutir como a "violência difusa" (Tavares dos Santos, 2009) configura as dinâmicas dos atos infracionais e como estes se vinculam a uma "sociabilidade violenta" (Rolim, 2016) na qual ambas permeam diferentes esferas da sociedade, no entando mais visível e perceptível nestes jovens e em suas práticas. Além destes autores, o referencial teórico utilizado aborda a sociologia configuracional e relacional de Norbert Elias e as noções de juventude, a apartir do diálogo entre Pais (2003) e Andrade (2007).

O desenvolvimento do trabalho está organizado em três tópicos: Inicialmente será discutido a escolha teórica da noção de juventude, em seguida a percepção dos agentes do Estado em relação os atos infracionais e as categorias elencadas pelos agentes institucionais relacionadas com o envolvimento e a pŕatica de atos infracionais e, finalmente, os dados disponibilizados no Plano de Atendimento Municipal Socioeducativo (PAMSE).

\section{Considerações sobre atos infracionais e violência}

A preocupação em torno da segurança pública tem pautado os discursos das lideranças políticas de modo geral há muito tempo, com recorrente preocupação sobre a participação de adolescentes menores de idade em casos de violência pelo país. De tempos em tempos, a discussão sobre a redução da maioridade penal é retomada, mais recentemente pelo Congresso Nacional em 2015 e em 2017.

No Brasil, desde a publicação do Estatuto da Criança e do Adolescente na década de 1990, o termo "adolescente em conflito com a lei" é utilizado. Segundo dados do Cadastro Nacional de Adolescentes em Conflito com a lei, no ano de 2016, 189 mil adolescentes respondiam por 222 mil atos infracionais. As pesquisas também demonstram, ao mesmo tempo, que este grupo que, em sua maioria vítimas dessa violência também a protagoniza. $\mathrm{O}$ "Mapa da Violência 2016: homicídios por armas de fogo no Brasil" demonstra que aproximadamente $90 \%$ das pessoas vitimizadas por armas de fogo são homens e, além disso, aproximadamente, $26 \%$ da população total do país no período analisado, possuía entre 15 e 20 anos de idade, mas a participação juvenil no total de Homicídios por Arma de Fogo mais que duplicou o peso demográfico dos jovens na qual 58\% correspondia a vitimização juvenil (WAISELFSZ, 2015, p. 49).

Este trabalho, insere-se no campo de estudo da Sociologia, especialmente a subárea da Sociologia da Juventude e da Sociologia da Violência. A fim de compreender uma parcela desta realidade, o presente artigo apresentará alguns elementos que compoem as configuarões 
dos atos infracionais e da violência, especialmente a partir da perspectiva dos agentes ${ }^{4}$ do campo sócio-jurídico ${ }^{5}$, em Pelotas-RS.

\subsection{Que juventude é essa? Apontamentos sobre a perspectiva teórica sobre juventude(s)}

Embora este artigo enfoque a percepção dos agentes sociojurídicos sobre os atos infracionais e sua relação com a violência, faz-se necessário primeiramente discutir a perspectiva teórica de juventude escolhida para a pesquisa realizada. $\mathrm{Na}$ dissertação Os jovens em conflito com a lei na perspectiva do sistema de garantia de direitos: percepções a partir da rede socioeducação e do sistema judiciário em Pelotas-RS, optou-se pelo diálogo entre as noções de juventude de Pais (2003) e Andrade (2007), pois as narrativas dos agentes e as observações realizadas apontaram para um entrelaçamento entre as duas perspectivas.

O surgimento e as transformações em torno da conceituação sobre infância, adolescência e juventude estão relacionadas com a dimensão histórica dos processos sociais, bem como o modo que a sociedade, o Estado e as próprias ciências sociais lidam com esses agentes sociais ao longo dos debates sociais e acadêmicos ${ }^{6}$. Isso demonstra que existiram e ainda existem diferentes maneiras de reconhecer quem são esses sujeitos e o universo do qual fazem parte.

O conceito juventude foi abordado a partir de diferentes lentes teóricas e diversas áreas do conhecimento. Inicialmente os primeiros esforços dedicados a juventude datam do século XVIII, na qual este contingente deveria se integrar a sociedade (Tavares, 2012). Dentre as diversas teorias que buscam discutir esse conceito destacam-se algumas como a Escola de Chicago, as teorias funcionalistas e os Estudos culturais, na década de 1970.

Surgem, no contexto de industrialização problemas sociais como o da violência urbana dentre elas o que foi caracterizado de criminalidade juvenil e as principais hipóteses deste

\footnotetext{
${ }^{4}$ Optou-se pelo termo "agente" porque este trabalho envolve o Estado e as pessoas que atuam nele e portanto possuem uma disposição no campo sócio-jurídico e atuam numa configuração estatal específica.

${ }^{5}$ Conforme Marinho (2012) o conceito de campo sócio-jurídico envolve duas lógicas, dois saberes, dois agentes principais: os profissionais da esfera judiciária e da esfera socioeducativa. Situação proveniente do modelo de proteção integral e seu paradigma da educação/sanção.

${ }^{6}$ A noção de adolescência está vinculada especialmente as áreas da saúde, como psicologia e medicina, e aborda dimensões centradas no desenvolvimento psico e biológico do ser humano, enquanto a noção de juventude(s) está vinculada a área das ciências sociais, especialmente a Sociologia, que busca discutir, problematir e por vezes conceituar, o coneito ou categoria juventude. Na Sociologia da Juventude, existem diversos autores(as) que discutem a temática da juventude como Abramo (1997), Groppo (2015), Novaes (2007), Mannheum (1982), Sposito (2009), entre outros(as). Devido ao limite de páginas do artigo e da proposta do mesmo, as diversas perspectivas sociológicas não serão abordadas demasiadamente nessa submissão e sim apenas aqueles que foram consideradas na dissertação de mestrado defendida junto ao PPGS/UFPel.
} 
período vinculam a relação da criminalidade com a pobreza (Tavares, 2012). Esse entendimento estava vinculado a perspectivas funcionalistas de integração do jovem na sociedade que marcaram os primeiros estudos da Escola de Chicago, preocupados especialmente com o desvio social.

Os estudos culturais estão relacionados ao Centre for Comtemporary Cultural Studies (CCCS), na Inglaterra, no qual um dos teóricos mais conhecidos dessa corrente foi Stuart Hall. Na década de 1960 o CCS inaugura uma nova perspectiva que valoriza a pesquisa etnográfica articulada com a teoria marxista, criticando abordagens especificamente estruturalistas, contribuindo assim com o estudo das subculturas juvenis (Tavares, 2012).

No Brasil, a juventude como categoria social surge por voltas das décadas de 1950 e 1960, quando havia um setor industrial em desenvolvimento e o incentivo para mudanças para uma ordem capitalista. Aos poucos, vai se rearranjando novas configurações sociais no mundo do trabalho assalariado, dentre o aumento da contratação de adolescentes e jovens.

"No país, outra vertente desenvolvida na direção de uma Sociologia da Juventude estava voltada para o estudante universitário localizado na classe média" (Tavares, 2012, p. 189). Porém, a partir os nos 80 e 90, inicia-se uma diversidade teórica metodológica nos trabalhos sobre a juventude, com influência dos estudos culturais e o interesse-se pelas subculturas juvenis, assim como pelos problemas relacionados à violência (Tavares, 2012).

Faz-se válido ressaltar que a UNESCO terá papel preponderante na agenda de pesquisas acadêmicas e políticas públicas que envolvem os jovens, a partir da década de 1990, incentivando a discussão e reflexão sobre questões vinculadas a juventude. Surge uma nova perspectiva onde o jovem deixa de ser desviante e passa a agente social, vítima e causadora da violência, o que o inclui numa perspectiva de vulnerabilidade social (Tavares, 2012).

Dois pensadores se destacam nas abordagens teóricas sobre a juventude

\begin{abstract}
Sposito (1994) e Pais (2005), dentre outros, discutem uma abordagem teórica e metodológica considerando a juventude não simplesmente como subcultura ou sujeitos desviantes, mas levando em consideração a ideia de pluralidade de suas manifestações e sua participação efetiva em termos estruturais. Esses estudos questionam as perspectivas mais tradicionais sobre estudos da juventude. Para tanto, os autores se voltam para a complexidade intrínseca dos modos de vida dos jovens, definidos como "culturas juvenis" (TAVARES, 2012, p. 189).
\end{abstract}

Ao serem interpelados sobre quem eram os jovens atendidos nas MSE e como os reconheciam, alguns elementos foram recorrentemente repetidos por diferentes entrevistados, enquanto outros elementos foram citados por poucos ou apenas um(a) dos interlocutores. As categorias em comum que envolveram o reconhecimento em relação a esse grupo juvenil envolve: condição juvenil; condição socioeconômica do jovem e/ou da família; a evasão 
escolar; a droga (para consumo e/ou como renda); a ausência de perspectiva de futuro; ausência de documentação; a percepção de que eles pertencem a "outro mundo"; a acentuação na necessidade de mudança de comportamento; envolvimento com o tráfico; as oportunidades oferecidas e não aproveitadas; a descentralização do foco no ato infracional e a ênfase no sujeito; sinceridade sobre o que fizeram; ausência de limites e dificuldade de lidar com regras e a morte violenta de vários deles.

Desse modo, durante o desenvolvimento da pesquisa e elaboração da dissertação, foi possível obervar que os jovens a quem os agentes se referiam pertenciam ao mesmo tempo a uma coletividade geral e mais abrangente comum a todos(as) aqueles com determinada faixa etária que compartilham determinados desejos e necessidades (como, por exemplo, de aquisição de bens de consumo e pertencimento a determinado grupo) e, concomitantemente, também se diferenciavam e constituiam um grupo com características comuns entre si, mas com singuralidades se comparado ao grande grupo "juventude".

Assim, defende-se como possível e importante o diálogo entre a noção de Pais (2003) e Andrade (2007), assumindo-se com isso o risco de aproximar duas perspectivas que, a rigor, encontram-se em correntes diferentes. No entanto, ao ousar trabalhar com ambos, busca-se contemplar tanto a dimensão etária que envolve essa parcela da população, como reconhecer que há uma diversidade de expressões juvenis. Além disso, a noção de "juventudes" de Andrade (2007) colabora para discutir as homogeneidades entre os adolescentes que encontram-se em cumprimento de medida socioeducativa e as singularidades em relação às outras juventudes.

Para Pais (2003) existem basicamente dois enfoques diferentes que envolve a noção de juventude. O primeio, denominado "corrente geracional", define as chamadas culturas juvenis a partir do seu critério etário, ou seja, em relação à "geração adulta", na qual a centralidade está na continuidade/descontinuidade dos valores e da reprodução/transformação social. A outra perspectiva, segundo Pais, é a "corrente classista", que enfatiza a origem social destes grupos, tendo, portanto, um enfoque nas diferentes classes sociais em que os grupos juvenis se inserem.

Para Doutor (2016) José Machado Pais (2003) na sua obra intitulada "Culturas Juvenis"

o autor defende que a juventude aparece socialmente dividida em função das suas origens sociais, perspectivas e interesses. Contudo, a juventude pode ser homogénea se a compararmos com outras gerações ou heterogénea se a encaramos como um 
conjunto de atributos sociais que diferenciam os jovens uns dos outros (Doutor, 2013, p. 162).

Por outro lado, Andrade (2007) aborda a juventude como uma experiência etária específica, no sentido de que há uma idade ou uma temporalidade juvenil e "ser jovem é uma condição particular, mas não homogênea [...]: existem várias juventudes vivendo esta experiência etária que se relaciona com diferentes formas de sociabilidade" (TRANCOSO; OLIVEIRA, 2016, p. 285).

As diversas abordagens conceituais ou problematizações sobre a juventude enfatizam diferentes perspectivas, seja da juventude como fase de transição para a vida a adulta; definida com faixa etária específica ou ainda como desviante. Algumas concepções acentuam as características psicossociais, enquanto outras buscam caracterizá-la como uma categoria sociológica passível de análise. As narrativas dos entrevistados, demonstram que não existe apenas um modo de reconhecimento sobre quem são os jovens atendidos nas MSE, assim como que existem diferentes perspectivas sobre eles, vinculadas as diferentes noções de juventude.

Neste tópico optou-se em não aprofundar a discussão sobre o reconhecimento dos agentes em relação aos jovens em conflito com a lei, e sim apresentar brevemente um panorama geral das correntes sociológicas que abordam a temática da juventude e justificar a escolha de Pais (2003) e Andrade (2007) por entender que essa parcela juvenil constitui uma cultura juvenil específica, vinculada a dimensão de classe, e ainda assim, ao mesmo tempo participa de um grupo maior se considerada a faixa etária e a existência de uma "temporalidade juvenil" que também precisa ser levada em consideração para compreender que juventude é essa, atendida nas MSE pelos agentes sócio-jurídicos.

\subsection{Os atos infracionais, relações e causas na perspectiva dos agentes do campo sócio- jurídico}

Considera-se importante entender como os agentes institucionais ${ }^{7}$ co-responsaveis pela elaboração, planejamento, execução e fiscalização das MSE percebem os atos infracionais cometidos por esses jovens, seja em relação aos atos mais cometidos, os que mais chamam sua atenção e com o que, em suas perspectivas, estão relacionados, pois estes sujeitos trabalham diretamente com os adolescentes em conflito com a lei, além de influenciarem na

\footnotetext{
${ }^{7}$ Os nomes utilizados são fictícios para preservar a identidade dos(as) entrevistados(as).
} 
elaboração e efetivação de políticas públicas para esssa parcela da população. Assim, através das entrevistas semiestruturadas realizadas e da observação direta das reuniões da Rede Socioeducação, se pode elencar os fatores recorrentemente mencionados como influenciadores para o cometimento de ato infracional, a saber: o tráfico de drogas, a violação de direitos na infância e na adolescência, a configuração familiar, a baixa escolaridade e evasão escolar e a condição socioeconômica do jovem e de sua família.

Além disso, entende-se que, ao falar dos atos, das suas causas e relações com o contexto de vida desses jovens, a dimensão do reconhecimento também permeia as falas dos entrevistados, o que colabora para dimensionar de modo mais amplo sua visão em relação a esse grupo juvenil. Os elementos identificados serão discutidos nos próximos itens. A fala do Renato reúne várias dimensões que foram elucidadas por diferentes agentes do campo, em relação à complexidade que envolve a prática de atos infracionais:

\begin{abstract}
As causas são muito complexas que levam o adolescente a praticar ato infracional. Normalmente o pano de fundo tem sempre uma questão relativa ao grupo familiar. Normalmente esse grupo familiar é totalmente desajustado ou desajustado em parte. Isso gera problemas na imposição de limites... A questão financeira e patrimonial também. Normalmente (não é uma regra), mas a maioria das famílias dos adolescentes têm pouco poder aquisitivo. Nessa fase que tu queres adquirir e ter coisas e aí não tem essa possibilidade. Tanto que a maior parte dos atos infracionais são patrimoniais, mas há também atos infracionais de homicídio, estupro e outras coisas mais. Então esse [do qual estava falando] é apenas um dos fatores. Então o desajuste da família, a questão patrimonial, a questão da drogadição, a questão da ausência de expectativa de construção de um futuro melhor pelos meios tradicionais, a evasão escolar, o abandono da escola, baixa auto-estima, a violência intrafamiliar. Tudo isso é fator de construção para a prática do ato infracional, não tem um fator só.
\end{abstract}

\title{
2.2.1 Atos Infracionais mais violentos
}

Em relação aos atos infracionais cometidos pelos adolescentes, há a percepção do agravamento dos atos. No que refere-se à percepção de quais atos são mais cometidos, as explanações apresentam diferenças, pois alguns mencionaram a maior incidência de homicídios, enquanto outros citaram o roubo como o ato mais recorrente.

Hoje os adolescentes já iniciam praticando roubos, ou seja, né, subtração com violência ou grave ameaça à pessoa. $\mathrm{O}$ ato infracional de furto é muito raro acontecer ou talvez as pessoas já nem registrem porque acham que aquilo não é importante, mas assim, na prática não se tem ...hã... é muito difícil ter furtos ou qualquer ato infracional sem violência ou grave ameaça, hoje. Claro o porte de arma, o tráfico, né que na verdade são sem violência também são atos infracionais graves e que acontecem bastante, e que dão ensejo a medidas em meio aberto, ainda né...(Larissa). 
A explanação de Larissa aborda a relação do tráfico de drogas com o cometimento de ato infracional pelos adolescentes. O uso de substâncias psicoativas ou envolvimento com o tráfico de drogas é delegado pelos agentes como um dos fatores primordiais atualmente para o envolvimento com delitos, seja o porte de arma, o roubo ou o homicídio, de modo que o uso de drogas é algo recorrente entre esses sujeitos. Segundo os demais entrevistados, há uma relação entre roubar para sustentar o vício e aos poucos ir se envolvendo com facções criminosas, o que envolve os atos já comentados como também o fato de morrerem de forma muito precoce e inesperadamente. As entrevistas apresentam de modo geral o tráfico de drogas e sua relação com os atos infracionais.

Conforme uma interlocutora do campo jurídico relatou "o homicídio mesmo tem relação muitas vezes com o tráfico, dívida de tráfico e é um propulsor para outros atos como o roubo e latrocínio"; por exemplo. Outros interlocutores também abordaram essa questão ao mencionar os fatores que estavam relacionados aos atos, conforme pode ser observado abaixo:

Ao tráfico de drogas. Drogas de uma forma geral e muito especificamente ao tráfico de drogas... porque o adolescente que usa drogas ele rouba ele acaba praticando um rouba pra sustentar o vício dele. $\mathrm{O}$ adolescente que mata alguém.... Se for investigar a fundo isso a maioria dos homicídios que nós temos ali no CASE são homicídios praticados em decorrência do tráfico de drogas. Ou matou um da facção contrária, ou matou porque a facção matou o irmão, matou um primo e aí eles foram lá e mataram os outros....(Lorena).

maioria é roubo, que é a subtração com violência ou grave ameaça e tão relacionado ao uso de drogas, com certeza. Porque eles subtraem um celular, uma pequena quantia em dinheiro que é bem pra sustento do vício. Dá bem para ver. (...) Ou como a gente vê em Rio Grande (RS) mesmo, que famílias de diversas gerações estão envolvidas com o crime, não é porque ele vai cair na nossa mão que a gente vai ter o poder de transformar toda essa história e deixar ele bonzinho. Isso aí não acontece, né? (Larissa).

A iniciação criminal foi abordada por Rolim (2016) ao estudar jovens em cumprimento de MSE de internação no RS. Conforme Rolim (2016, p. 163), “a maioria dos jovens internos na Fundação de Atendimento Socioeducativo (FASE) por delitos com grave violência vinculou suas trajetórias ao tráfico de drogas desde o início da adolescência”.

A pesquisa realizada recentemente que originou o livro A Formação de Jovens Violentos: Estudo sobre a etiologia da violência extrema (ROLIM, 2016) colabora para compreender tanto o perfil agravado mencionado por esses interlocutores, assim como identifica a inserção no tráfico de drogas como uma constante presente na vida desses adolescentes. Embora não seja objeto desta pesquisa especificamente os adolescentes em internação, as narrativas desse grupo de interlocutores se dirigiram muito mais a esses jovens, 
do que aqueles, em medida em meio aberto, ainda que quando solicitados tenham abordado as outras MSE.

\subsubsection{Droga, uso, consumo e renda}

O uso de substâncias psicoativas foi abordado pelos agentes do Fórum, da Defensoria Pública e do Mimistério Público como uma característica recorrente referente a esses adolescentes, especialmente o uso da maconha. Dentre os múltiplos fatores elencados como concorrentes para o envolvimento com atos de violência ou a criminalidade, a "droga" foi mencionada tanto pelos agentes do Sistema de Garantias de Direitos como por outros membros da Rede Socioeducação.

Sem dúvida uma multiplicidade de fatores... eu vejo assim, primeiro lugar a questão das drogas, existe um acesso muito fácil ao acesso a drogas e drogas forte, principalmente de consumo e isso é muito preocupante, você vê jovens de 14,15 anos usando drogas pesadas principalmente o crack que é uma droga que vem assolando as comunidades mais pobres, a pessoa sem nenhuma estrutura emocional, material, pra lidar com isso, com o filho drogado. Você tem crimes sexuais que são praticados muitos envolvendo a questão de drogas, as drogas levam a praticar crimes, se o adolescente não estive sob o efeito de drogas, provavelmente não praticaria $o$ ato. (...) A droga é um problema de saúde pública muito grave e atinge todas as esferas, principalmente a nossa população de baixa renda, não que a população de alta renda, ela usa drogas também, obviamente que sim, mas ela tem condições de lidar com problema da droga de forma muito melhor... você tem aqueles que usam drogas de forma eventualmente, mas ele tem o suporte pra fazer... (Jorge).

O envolvimento de adolescentes e jovens com a violência no Brasil tem suscitado muitos estudos tendo em vista a seriedade do problema, especialmente porque a violência tem se traduzido constantemente em práticas letais (ROLIM, 2016). Segundo o autor

o conhecimento acumulado indica que lidamos com fenômeno universal e que os atos delituosos - violentos ou não - se concentram desproporcionalmente, independentemente das diferenças culturais, entre pessoas em uma faixa etária que se se prolonga da metade da adolescência até os primeiros anos após a segunda década de vida (ROLIM, 2016, p. 109).

O envolvimento com essas práticas delituosas tem sido discutido por diversas áreas como a Psicologia, Criminologia, Sociologia, Educação, a fim de compreender o que leva o envolvimento com atos infracionais. As abordagens sobre o tema enfatizam diferentes perspectivas, Rolim (2016, p. 114-115) afirma, por exemplo, que "o estágio atual das pesquisas etiológicas sobre crime e violência não permite identificar com precisão as conexões entre as variáveis macroestruturais (classe social, etnia, mobilidade) e micro estruturais (interação entre pais e filhos, disciplina) com o controle social informal". Isto 
exigiria uma nova teoria criminológica que, para Sampson e Laub (1995), deveria incorporar os seguintes elementos: “1) família e escola (...);2) os comportamentos antissociais das crianças e adolescentes (...); 3) vínculos informais no mundo adulto (casamento, nascimento de filhos e emprego estável)". Segundo Rolim (2016), a teoria desses enfatiza os efeitos do controle informal na infância, na adolescência e no mundo adulto como centro de seu modelo teórico.

Conforme Rolim (2016, p. 122)

Ao tentar explicar as origens da delinquência, os criminólogos tem lidado ou com fatores estruturais (pobreza, famílias desconstituídas), ou com variáveis processuais (como vínculos aos pais ou aos professores). Para Sampson e Laub (1995), essa separação é um erro. Eles sustentam que o controle social informal derivado da família ou da escola media os efeitos das variáveis tanto estruturais quanto individuais. Assim, por exemplo, desvantagens no plano econômico social impactam a vida das famílias, produzindo efeitos debilitadores sobre o cuidado com os filhos; o mesmo se pode dizer no sentido inverso: determinadas decisões tomadas pelos pais - separação, mudança de cidade etc. - podem abalar o processo de formação das crianças, gerando efeitos desagregadores.

Para alcançar essa dimensão mais ampla seria necessário focalizar os estudos para a) socialização familiar (disciplina, supervisão e vínculo com os pais); b) o vínculo com a escola; c) a influência de amigos ou irmãos envolvidos no crime (ROLIM, 2016). Para Sampson e Laub (1995) apud Rolim (2016), “a estrutura social influencia as dimensões do controle social informal exercido pelas famílias, o que por seu turno, explica as variações na delinquência".

\subsubsection{As configurações do ato infracional: a família e a escola}

Nessa teoria, o papel das famílias assume uma importância maior ao passo que quatro fatores são elencados colaboradores para a delinquência entre os jovens, a saber: a disciplina errática, ameaçadora e fortemente punitiva por pais e mães; supervisão fraca; rejeição das crianças pelos pais; vínculos emotivos frágeis entre pais e filhos. Nesse contexto, a estrutura social é compreendida como uma influenciadora indireta por meio de seus impactos nas famílias (ROLIM, 2016).

Em relação à escola, na perspectiva do controle social, assim como a família, essa instituição é importante para a socialização desses sujeitos na prevenção do comportamento delinquente, pois se entende que os professores estão melhor preparados para "lidar" com esse adolescente além de serem legitimados pela autoridade da escola. Além disso, o vínculo com a escola seria um fator de prevenção à prática de ato infracional, por exemplo. Rolim (2016) ao abordar a dimensão escolar discute os dados do estudo dos Gluecks que, segundo ele, 
demonstraram que os jovens envolvidos com a delinquência possuem uma tendência muito maior a não concluírem seus estudos, do que os jovens não envolvidos. Isso remete a outro elemento citado nas entrevistas: a evasão escolar ou a defasagem escolar dos adolescentes em cumprimento de medida socioeducativa na Comarca de Pelotas.

\begin{abstract}
Primeira coisa... o que mais salta aos olhos é a baixa escolaridade. São guris que não frequentam a escola ou se frequentam de uma forma muito precária porque a grande maioria deles chega ali no CASE com uma escolaridade baixíssima e a escola... quando eu falo a ausência de escolaridade não é só só a questão da escolaridade formal, é a escola enquanto instituição de ensino, de preparo pro trabalho de vinculação com pessoas, com professor, com pessoas que muitas vezes servem de exemplo, visualiza no professor aquela figura da pessoa que te passa conhecimento. É a escola de uma forma bem abrangente (Lorena).

Também a questão envolvendo uma grande quantidade de adolescente envolvidos com a evasão escolar, então adolescentes que estão fora da escola, com pais ou uma mãe que não tem autoridade nenhuma sobre o adolescente, absolutamente nenhuma, então isso obviamente acaba esbarrando na polícia, e posteriormente na justiça, que é o único momento que o adolescente tem um freio (José).
\end{abstract}

Na perspectiva desse promotor "Criança que não frequenta escola, adolescente que não frequenta escola é adolescente problema... é como se costuma falar: adulto que não quer trabalhar e criança que não quer brincar, alguma coisa tem de errado".

Em sua pesquisa de doutorado, Rolim (2016) discute a "escola como distância" e apresenta os dados disponíveis sobre escolarização dos adolescentes e jovens adultos privados de liberdade na Fase do RS. Dentre as observações do autor, demonstra que o conjunto dos internos no RS possuem uma média de anos de estudo significativamente mais baixa que as médias estadual e nacional. Segundo as informações do Relatório de auditoria do Tribunal de Contas do Estado (TCE-RS), a média de anos de estudo para os internos da FASE é de 6,59, enquanto a média estadual e nacional é de 8,75 e 8,30, respectivamente.

A taxa de defasagem escolar também foi abordada. O Relatório constatou "que todos os internos da Fase possuem defasagem escolar, com um déficit que ultrapasse em muito mesmo as realidades vividas pelas famílias mais pobres do RS e do Brasil. Na FASE, a diferença entre a série adequada e a série efetiva é de, aproximadamente, cinco anos" (ROLIM, 2016, p. 173). A questão ilustrada por Rolim envolve diversas experiências vivenciadas pelos adolescentes em cumprimento de medida de internação no RS, e demonstra proximidade com a realidade do município de Pelotas em relação a dimensão da escolarização e educação dos jovens atendidos pela Rede Socioeducação.

\title{
2.2.4 Classe/renda/condição socioeconômica da família
}


Outro elemento considerado pertinente para a prática do ato infracional é o meio social onde esse adolescente está inserido. O bairro em que reside, a presença de facções criminosas vinculadas ao tráfico de entorpecentes, o não acesso e garantia a direitos como saneamento básico, por exemplo, foram mencionados como situação propícia para o envolvimento com delitos, somados a outros itens discutidos até o presente momento.

\begin{abstract}
Pra mim esse é um grande problema porque ele se cria num local que acaba muitas vezes induzindo a participação dele em ato infracional, que se ele não estivesse ali ele não teria praticado e aí ele vai pra dentro do CASE ele sai exatamente pro mesmo lugar e todas aquelas circunstâncias que levaram ele a praticar o ato infracional continuam ali. Ás vezes a gente pensa "ah que absurdo a reincidência", mas assim é tu não querer enxergar uma realidade (...) a gente anda por esses bairros, o esgoto corre na frente da casa da pessoa, as pessoas não tem moradia, luz, não tem condição de comprar uma cesta básica pra sua família porque as pessoas não trabalham, não tem condições de tomar um banho pra procurar um emprego... não tem condições (Lorena). (...) e outra coisa também que nós estamos trabalhando aqui em Pelotas é a questão envolvendo o estudo de adolescente adulto porque o adolescente tem 16 anos, mas parou no quinto ano, ele está muito atrasado, então você leva ao EJA, que é aquela educação continuada de alunos que já ficaram muitos anos fora da escola pra você tentar recuperar esse tempo perdido. Muitos são encaminhados, mas se você não tem o apoio da família, um apoio... você não consegue fazer isso, porque muitas vezes os pais desse adolescente não conseguem compreender o alcance disso porque eles também não tiveram (...) (José).
\end{abstract}

Relacionado ao contexto de vida desses adolescentes que envolvem o local de moradia, a "desestrutura familiar" e a condição socioeconômica das famílias são elencados como fatores que contribuem para atos delituosos. Conforme um dos entrevistados "a pobreza ela leva a uma carência de acesso a digamos assim... a uma rede de assistência que as crianças e os adolescentes têm geralmente uma família mais provida de recursos, uma escola, um atendimento médico, um atendimento psicológico".

Aí varia um pouco. A gente teve casos lá em Rio Grande inclusive de adolescentes de classe média. Muito estimulados pela questão da ostentação. Então eles criaram um grupo e assaltava postos de combustível na época e colocavam nas redes sociais o dinheiro e com correntes, com joias, bebidas. Então tem essas duas, que a gente chama, assalto ostentação, que eles não precisam, mas que eles são estimulados pelo consumismo. Até aí mostra, fazem questão de mostrar, mas a maioria é classe baixa, com certeza (Larissa).

\title{
2.2.5 Violação de Direitos na Infância e na adolescência
}

A violação de direitos na infância, além de estar presente na percepção dos agentes sociais sobre os atos infracionais, também apareceu sendo considerado como um fator

\footnotetext{
${ }^{8}$ Termo utilizado pelos(as) interlocutores(as) da pesquisa.
} 
"importante" para o envolvimento com atos infracionais. Existe o reconhecimento entre os agentes da necessidade de investir na proteção, na garantia dos direitos na infância como forma de evitar o envolvimento com a criminalidade. A percepção sobre a violação de direitos constante na trajetória de vida desses jovens foi abordada diretamente por duas entrevistadas do campo jurídico:

\begin{abstract}
Uma série de violações desde a questão do atendimento pré-natal a gestante, começa aí na primeira infância, ausência de vaga em creche, escola, ensino público de baixa qualidade" (Lorena).

muitos deles não sabem escrever o seu próprio nome, não sabem sua data de nascimento, sabem só o ano que nasceram. Uma série de violação de direitos lá na infância e com isso menos estrutura para se desenvolver. É visível o grau de violação de direitos por isso entendo que é importante investir lá na proteção (Flávia).
\end{abstract}

O não acesso aos direitos fundamentais da criança e do adolescente, garantidos constitucionalmente pelo ECA, é percebido como fato comum entre aqueles que são atendidos pelo Judiciário e pelos serviços de execução da medida. Porém, embora identifiquem a violação de direitos tanto na infância como no contexto de vida atual dos adolescentes, percebido como fato importante para envolvimento com o ato infracional, voltam seu olhar para a infância ao retomar a importância de se investir na proteção, especialmente das crianças. Com isso, percebe-se a existência de uma ênfase e crédito à atenção básica, que não se faz em relação à garantia de direitos dos adolescentes e suas famílias que ao que tudo indica, continuam com seus direitos sendo violados no que se refere à saúde, educação, saneamento básico, etc.

\title{
2.2.6 A "Mudança de perfil" dos adolescntes
}

A mudança do perfil dos adolescentes também foi mencionada por diferentes entrevistados da Rede Socioeducação que trabalham ou trabalharam com as medidas em meio fechado ou em meio aberto, e da Delegacia de Proteção à Criança e ao Adolescente, conforme pode ser observado nos excertos abaixo:

(...) por exemplo em 2011 quando eu trabalhei esses seis meses na semiliberdade por outra instituição, eles já eram delitos, isso não é uma pesquisa com fonte, mas de lembranças minhas, mas era delitos mais leves e os adolescentes tinham um outro perfil. Ele tinha um perfil de muito mais humilde, de falta de acesso mesmo até sem roupa, eles não tinham roupa e nós estávamos sempre juntando doação pra dar um tênis, uma roupa, uma cueca, quando foi para 2014 quando iniciamos a semi liberdade por outra instituição, mudou bastante já o perfil, o perfil dos guris ali e ainda é hoje esse perfil na minha concepção, adolescentes que eu faço uma visita... uma casa muito humilde em bairros que eu não consigo entrar de carro, tenho que entrar a pé porque são becos mesmos, né, casas assim com a maioria de tábuas presas uma na outra não é nem um chalé direito nada, mas eles estão impecáveis, 
tênis Nike que nem eu sabia que existia de 600 reais na época que eu estava começando a trabalhar com eles, roupa de marca, correntes de prata e hoje eu acho que se mantém o perfil do adolescente, e eu também acho que o perfil do ato infracional também mudou de 2011 pra hoje (Fernanda).

A entrevistada, pertencente a Rede Intersetorial, ao abordar e mudança de perfil, faz essa comparação envolvendo um recorte de tempo maior, pois retoma o início da medida de semiliberdade no município. Na sua perspectiva, observa-se uma mudança no modo de vestimenta desses adolescentes. Anteriormente esses jovens, em condição de exclusão, possuíam dificuldades inclusive de vestimenta, conforme apontado por ela, o que mudou significativamente na sua percepção. Atualmente, é difícil encontrar um jovem nessas condições, embora permanecem em condição de exclusão, possuem de alguma maneira o acesso a esses bens de consumo.

Essa percepção conversa com a reflexão de outra interlocutora da Rede ao falar sobre sua primeira visão em relação aos adolescentes que cumpriam medida em meio aberto:

(...) quando me disseram "tu vais trabalhar numa equipe que atende adolescente infrator" eu fiquei "ah, puxa..." eu me lembro a primeira vez que eu vi um deles chegando pra atendimento ... eu esperava aquele adolescente maltrapilho sujo e tal, e eles chegam com todo um visual, roupa de marca, cheiroso tudo mais, aí eu olhava assim... puxa como os nossos preconceitos são também confrontados... E isso também sempre me chamou muito atenção como os apelos da sociedade de consumo está tão presente nesse grupo de adolescentes, isso vai se ver muito assim eles querendo se inserir nesse mundo da adolescência normal, que usa tênis de marca, adolescência normal pensando sociedade de consumo né, que usa tênis de marca, que usa um boné da marca tal e correntão. Então tem todo um visual, uma estética de um certo tipo de vida que eles querem acessar. Aí tu vais ver esse adolescente lá no CREAS na hora do atendimento desse jeito e aí tu faz uma visita domiciliar na casa dele e ele mora num barraco que nem telhado tem, nem banheiro, mas ele tem um celular também da hora, entende? Esse acesso também me chamou muita atenção esse acesso que eles querem ter a uma sociedade de consumo no contexto de vida deles, eles não tem. Então eles vão ser atraídos pelo mundo do crime e do tráfico como uma possibilidade de ganhar dinheiro e acessar essas coisas (Bruna).

Desse modo, o que parece ser reconhecido como "mudança no perfil" não é a condição socioeconômica, mas o envolvimento com o tráfico de drogas, o que também está relacionado com os tipos de atos infracionais cometidos, de caráter mais gravoso, por exemplo, como o de homicídio. Assim, ao citar a mudança de perfil, essa narrativa está atrelada aos tipos de atos infracionais cometidos e não a evasão escolar que historicamente é citado como algo pertinente a vida desses jovens, por exemplo. Outra profissional da equipe técnica da MSE de semiliberdade também menciounou esse aspecto:

(...) a questão do perfil dos adolescentes mudou bastante, tem se agravado muito. De lá pra cá... eu lembro que na época do instituto nós tínhamos crimes, atos infracionais graves violentos, mas não tanto como a gente tem hoje. Hoje a maioria 
dos adolescente estão envolvidos em alguma faç̧ão ou pertencem a algum grupo e isso atrapalha um pouco o andamento da medida, faz com que muitas vezes eles evadam da medida, não consigam cumprir. Acho que muito em função do tráfico mesmo de quanto isso tem crescido aqui em Pelotas (Paula).

Uma das interlocutoras da Delegacia de Proteção à Criança e ao Adolescente percebe outras características, segundo ela:

Eles estão ficando cada vez mais perigosos, audaciosos e destemidos. Isso aí eles estão (Gilca)

Por outro lado, uma das profissionais entrevistadas discorda parcialmente da percepção de que houve uma mudança de perfil dos adolescentes, tanto em relação aos atos como em relação às suas condições socioeconômicas. Ela ressalta o aumento desses jovens envolvidos com o tráfico de drogas:

Percebo o seguinte... embora exista esse discurso eu acho que não existe uma diferença muito grande em relação aos atos infracionais. Se a gente for olhar os números mesmo, a gente vê que não varia muito na verdade os atos infracionais daquele tempo são os mesmos de agora, em proporção também, roubo principalmente, depois vem furto e outras coisas de envolvimento com o tráfico. O que eu acho que é diferente é que naquele período era um pouco menos envolvimento deles com o tráfico porque hoje o que a gente vê é que o roubo tem uma ligação com o tráfico também, então eu acho que a gravidade dos casos e o risco que eles estão correndo é maior por causa disso. Muito raramente vai ver aquele adolescente que só "bate" carteira. Hoje em dia ele está inserido num grupo que tem uma lógica... aí o roubo vai alimentar o tráfico ou ele diretamente ou envolvido com o tráfico, com a venda e o consumo às vezes também. Eu vejo que hoje eles estão em um contexto maior de risco por causa disso por causa das próprias regras do tráfico, por causa da imaturidade deles muitas vezes se envolvem em situações que gera morte, muitos foram assassinados nesse tempo, ameaçados, às vezes tem que sair da cidade por conta desses conflitos do contexto do tráfico. Isso eu acho que mudou um pouquinho agora os tipos de atos infracional eles são os mesmos né, mas o plano de fundo, o contexto territorial é que está mais violento (Bruna).

De modo geral o "perfil" dos adolescentes atendidos nos centros que executam as MSE aproxima-se do que pesquisas desenvolvidas em bairros populares de várias capitais brasileiras apontam: o crescimento da vulnerabilidade dos jovens e as ameaças à segurança pessoal no cotidiano de suas existências. Conforme Koury, as pesquisas

apontam também para o aumento das transgressões entre os joven habitantes dos bairros populares, em pequenos furtos, assaltos a mão armada, envolvimento com drogas e prostituição; vagar pelas ruas do bairros ou da cidade onde moram para zoar e mesmo intimidar o passantes, que normalmente os evitam, quando não os agridem o demonstram expressões de medo (KOURY, 2011, p. 472). 
Para melhor compreender o agravamento do perfil desses jovens, faz-se necessário perceber a grande questão da cultura da violência que, no Brasil, envolve os enormes problemas ligados, sobretudo, à escassez e ao desvirtuamento de recursos para a educação, saúde e geração de empregos, e o desvio para ações ligadas à indústria e cultura da violência ( KOURY, 2011). Nessa perspectiva, a ampliação da condição de exclusão

sobretudo entre os jovens, onde as relações pessoais, institucionais e sociais se tornam incertas, sujeitas à concorrência desenfreada, em que a regra é não ter regra e tudo vale por "um lugar ao sol", e preenchidas pelo medo do outro, ampliando as possibilidades de tensão intra e extraclasses (KOURY, 2011, p. 481).

Para Castro (2009), a recorrência na identificação dos jovens com comportamentos violentos e a explicação de certos comportamentos a partir de questões relativas à violência são elementos que se destacam em diversos textos que abordam a relação entre juventude e violência. Essas associações podem ser articuladas à violência intrafamiliar, à inclusão social por meio do consumo e associação à gangues. Todas essas percepções articulam-se nas entrevistas realizadas com aqueles que trabalham diretamente no atendimento a esses adolescentes. Porém, deve-se ressaltar que parecem existir diferentes graus de violência praticados pelos adolescentes, o que se faz atenção para não caracterização desses adolescentes como uma totalidade de perfil mais gravoso, considerando uma homogeneidade naquilo que os agentes entendem como violência.

Ao reunir todas as situações e fenômenos descritos como violência em projetos que visavam atender jovens em condição de exclusão, Castro (2009) constata uma polissemia das situações e fatos considerados violentos. Esta gama de possibilidades foi agrupada da seguinte maneira: 1) Violência como ato de força; 2) Violência como resultado de conflitos sociais; 3) Violência como instrumento de regulação; 4) Inata ao ser humano; 5) "Fato social total" e 6) Violência e exclusão social.

Partindo dessa classificação buscou-se identificar com quais delas o reconhecimento do caráter mais gravoso desses jovens estava relacionado e percebeu-se que dentre os entrevistados da rede socioeducação que mencionaram a questão da violência como característica agravante desses jovens, três deles podem ter suas narrativas vinculadas à noção de "Violência e exclusão social", onde a explicação da violência ocorre a partir da combinação entre outras terminologias e conceituações sobre a organização da vida social, como pobreza, desigualdades econômicas e sociais e diferenças culturais. No entanto, os temas deste conjunto não chegam propriamente a configurar uma definição de violência, limitando-se a explicar certos atos de violência, a partir das causas e efeitos gerados por 
outros processos e eventos sociais. Outras duas perspectivas situam-se em posições distintas. Uma delas atrela-se à violência como ato de força, reconhecendo que esses jovens estão mais "perigosos e destemidos" e a outra, à violência como resultado de um conflito social ao mencionar o porte de arma como uma forma de "defesa" ou possibilidade de resolução de conflito tendo em vista que esse jovem tem "bronca" na rua.

Por meio da elucidação das narrativas que citaram uma mudança de perfil associada a atos mais violentos, buscou-se discorrer que mesmo a mudança dos tipos de atos possuem atribuições de sentidos diferentes por aqueles que trabalham com os adolescentes em cumprimento de MSE. Além disso, parte da rede compartilha dessa sensação em relação ao perfil do adolescente que tem sido atendido no sistema socioeducativo, por isso, fez-se importante discutir essa percepção de alguns agentes, na medida que se busca compreender a realção da violência com os atos infracionais no município.

\subsection{Os atos infracionais em Pelotas-RS: reflexões a partir do Plano Municipal de}

\section{Atendimento Socioeducativo}

O Plano Municipal de Atendimento Socioeducativo (PMASE) tem como objetivo reconhecer a necessidade de avaliar e estruturar a rede de atendimento e proteção aos adolescentes em conflito com a lei, bem como a oferta de serviços a partir da realidade do Município, visando ainda à proteção integral aos adolescentes, por meio da execução de metas e ações nos seguintes eixos: 1) Gestão; 2) Qualificação do Atendimento aos adolescentes e às Famílias; 3) Participação cidadã dos adolescentes e 4) Sistema de Justiça e Segurança (PMSE, 2018). O PMASE tem como base o Plano Nacional Socioeducativo, documento que orienta o planejamento, a construção, a execução, o monitoramento e a avaliação dos Planos Estaduais, Distrital e Municipais Decenais do Sistema Nacional de Atendimento Socieducativo (SINASE, 2016).

Conforme Relatório do PMASE, em relação às MSE em meio fechado (internação e semiliberdade), é possível identificar o aumento dos atos infracionais de homicídio e tentativa de homicídio entre os anos de 2014 e 2018 que cumpriram medida de internação, conforme apresentado pelo CASE-Pelotas, na reunião de monitoramento do PMASE em agosto de 2018 na sede do MP. Os atos infracionais de maior incidência em Pelotas durante os últimos cinco anos são o roubo (121), seguido do homicídio (91) e depois tentativa de homicídio (46).

Em termos de proporção, o ato infracional de roubo apresentou maior índice em relação aos demais, em comparação com o mesmo período, nos anos de 2014 (33\%), 2015 (30,9\%) e 2017 (36,2\%). No ano de 2016, o roubo (21,5\%) ficou atrás do homicídio $(22,7 \%)$ 
e em 2018, esses dois atos correspondiam ao mesmo percentual $(27,5 \%)$. O terceiro ato infracional com maior incidência foi tentativa de homicídio, seguido do latrocínio.

Através das informações disponibilizadas pela Case/Pelotas pode-se observar um aumento de 5,9\% no número de homicídios, entre os anos de 2014 e 2018, e de $10 \%$ na tentativa de homicídios, enquanto o número de roubos e latrocínio diminuiu 5,5\% e 1\%, respectivamente. Através da ilustração desses dados é possível observar que as narrativas dos envolvidos no sistema de garantias em relação ao agravamento do perfil dos adolescentes em relação ao ato infracional no que tange a comarca de Pelotas vai ao encontro dos dados oficiais disponibilizados. Ao comparar o número de atos infracionais com grave ameaça à vida ou violência entre os anos de 2014 e 2018 houve um aumento percentual de 6\%, enquanto os atos infracionais sem grave ameaça diminuíram $1,5 \%$.

Isso demonstra que embora exista a percepção de que aumentaram consideravelmente os atos com grave ameaça ou violência, há de fato um aumento gradual nos números absolutos (46, 48, 57, 70 e 81), embora percentualmente esses atos representem um baixo nível de diferença se comparado os anos de 2014 e 2018 (6\%), inclusive com diminuição de atos dessa gravidade nos anos de 2015 e 2016. Os dados referentes às medidas em meio fechado demonstram que o roubo ainda é o tipo de ato infracional mais cometido, seguido do homicídio e tentativa de homicídio.

As narrativas de diferentes interlocutores que trabalharam ou ainda trabalham com as medidas vão ao encontro desses dados apresentados no diagnóstico. Conforme discutido por Lorena, agente do campo jurídico:

\footnotetext{
O que eu percebo: um aumento significativo, desde o período que eu vim pra cá até agora, principalmente do número de internações, e isso reflete o que? (...) é o reflexo do aumento da gravidade dos atos infracionais praticados. Porque teoricamente só vai ser recolhido o adolescente ... (...). Esse aumento da gravidade está relacionado ao tráfico de drogas, com certeza. Drogas. De uma forma geral e muito especificamente ao tráfico de drogas. Porque o adolescente que usa drogas ele rouba, ele acaba praticando o roubo pra sustentar o vício dele. $\mathrm{O}$ adolescente que mata alguém, se for investigar a fundo isso, a maioria dos homicídios que a gente tem no CASE ali, são homicídios praticados em função do tráfico de drogas. Ou matou um da facção contrária, ou matou porque a facção matou um irmão ou primo e aí eles foram lá e mataram os outros. Muito dentro desse contexto.
}

Outra interlocutora, assistente social, que trabalhou na equipe das MSE no CREAS, aproximadamente durante um ano e meio, também trouxe a questão do uso das drogas e o envolvimento com o tráfico de drogas, que está associado ao contexto dos atos infracionais e dos adolescentes que passaram pelo serviço ou ainda estão em cumprimento de medida, segundo ela atualmente 
(...) É muito difícil tu pegar um menino por não ter habitação. Se olhar os processos que a gente tem é homicídio, tráfico, já são coisas bem mais pesadas né. E é difícil ganhar do tráfico. É muito difícil ofertar alguma coisa que ele queira porque ele já está muito tempo evadido da escola, a evasão escolar é altíssima. (...) São raros os que estão na escola (Rose).

Ainda que o roubo seja $\mathrm{o}$ ato infracional mais praticado, alguns interlocutores relataram que esse tipo de ato item sido recorrente com maior imposição de sofrimento às vítimas, o que se apresenta como uma diferenciação nos últimos anos. O perfil "mais gravoso" apontado nas entrevistas é abordado por Rolim (2016) que discute a disposicionalidade violenta que se caracteriza como uma propensão determinada e legitimada socialmente por uma matriz valorativa cultural. Nas palavras do autor:

A definição que oferecemos para a disposicionalidade violenta é a de uma condição objetiva e mensurável que suporta e condiciona o caráter violento de comportamentos pressupostos pelos sujeitos diante da contrariedade tidas como significativas (ROLIM, 2016, p. 16).

Na pesquisa desenvolvida, Rolim estuda a "violência extrema", ou seja, aqueles jovens que praticaram atos infracionais com violência ou grave ameaça à pessoa. A operacionalização desse conceito envolve "a propensão variável de legitimar ações ilegais de punição física, entre as quais a de matar e a de agredir fisicamente independentemente de provocação" (ROLIM, 2016, p. 16).

A partir dos relatos nas reuniões e das entrevistas realizadas, entende-se que ao relatarem o perfil mais gravoso dos jovens, estes estão se referindo a uma parcela daqueles que ingressam no sistema socioeducativo. Não pode se afirmar que todos os jovens apresentam um perfil mais violento, mas sim que aqueles que têm sido encaminhados às medidas em meio fechado tendem a apresentar o que Rolim definiu como "disposicionalidade violenta”. No entanto, é necessário ressaltar que

ao selecionarmos agrupamentos de indivíduos de prática consideradas ilegais, lidamos, primeiramente, com naturezas muito distintas de fatos. Isto é verdadeiro não apenas quando tratamos de crimes diversos que podem corresponder - e frequentemente correspondem — a dinâmicas sociais em nada comparáveis, mas também quando lidamos com pessoas responsabilizadas pelos mesmos tipos penais (ROLIM, 2016, p. 49).

Com isso, ao abordar o "perfil mais violento" desses jovens, atenta-se para não correr o risco de considerá-los todos com disposicionalidade violenta, ainda que tenham praticado o mesmo tipo de ato infracional. Pois, apenas o fato de terem praticado crimes violentos não caracteriza essa conduta. Para Rolim (2016), há outras variáveis que envolvem essa 
caracterização como a brutalização na infância; a socialização familiar; socialização escolar e a socialização comunitária.

Buscando clarificar conceitualmente esse termo Rolim (2016) explica que

Ela corresponde a um conjunto de esquemas individuais de percepção e ação que foram construídos socialmente a partir de experiências concretas vividas pelos agentes e estruturadas pelas respostas por eles oferecidas a situação específicas e estruturantes. Nesse sentido, a disposicionalidade violenta poderia ser compreendida como um habtus violento, embora seja, mais do que isso, também um "campo" violento, para usar a nomenclatura de Bourdieu (ROLIM, 2016, p. 22).

Não será problematizado densamente o perfil desses jovens, mas sim, apresentar a análise sociológica de Rolim que colabora para compreender uma parcela da população juvenil de quem muitos sujeitos do sistema de garantias parecem se referir ao falar dos jovens em conflito com a lei no município de Pelotas. Assim, essa variável apresentada pelo pesquisador que envolve outras dimensões da vida dos socioeducandos ajuda a entender uma das formas de reconhecimento sobre os jovens com quem os(as) entrevistados(as) estabelecem relações, que configuram a execução das MSE, à medida em que a maneira como são percebidos por esses sujeitos interfere no processo da execução das medidas (sugestão de progressão ou não da MSE, tipo de medida etc).

Ao analisar os dados informados no relatório do PMASE, os atos infracionais dos adolescentes atendidos no CREAS (LA, PSC ou LA/PSC), entre os anos de 2014 e 2017, correspondiam a: $48,8 \%$ roubo; $25 \%$ Tráfico de Drogas; $16 \%$ furto e 9,4\% estupro. No Casemi, os atos infracionais mais cometidos, entre 2014 e 2018, por adolescentes em atendimento de medida de semiliberdade, correspondiam a: $66 \%$ furto; $11 \%$ homicídios; $10 \%$ estupro; $8 \%$ homicídios; $4 \%$ tráfico de drogas; $1 \%$ latrocínio. No mesmo período no CASEPelotas, os atos infracionais correspondiam a: Roubo 27,5\%; 22\% homicídios; $18 \%$ latrocínio; $11 \%$ tentativa de homicídio; $2,2 \%$ tráfico de drogas; $1,7 \%$ estupro e $0,7 \%$ porte ilegal de arma.

Pode-se observar em relação à medida de internação, o roubo como ato infracional mais cometido (29,6\%). Se comparados os anos de 2014 e 2018, esse tipo de ato diminuiu $5,8 \%$. Os atos infracionais de homicídio cresceram $6 \%$ e o de tentativa de homicídio $10 \%$, se comparados os anos de 2014 e 2018, enquanto o ato infracional de latrocínio oscilou nesse período, aumentando em 8,5\% em 2016, porém se comparados com o ano de 2014, diminuiu $1 \%$ e com o ano de maior incidência, diminuiu 9\%. Em relação à MSE de semiliberdade, os atos mais cometidos correspondem a roubo, 66\%, e o homicídio responde a 11\%. Em relação às medidas em meio aberto, o ato infracional de roubo corresponde a 48,8\%, em seguida, o 
tráfico de drogas corresponde a $25 \%$ dos atos infracionais cometidos pelos adolescentes atendidos no CREAS, e $16 \%$ corresponde a furto.

Ao discutir os dados, busca-se demonstrar que se observado o número de internações, de fato é perceptível o agravamento dos atos infracionais cometidos no ano de 2018, se considerado o número de homicídios e de tentativa de homicídio, porém o ato infracional de maior volume continua sendo o roubo. Em relação aos atos infracionais mais praticados por aqueles atendidos nas medidas de semiliberdade e em meio aberto, o roubo ainda configura o maior percentual de casos. Assim, diferente do furto onde algo é subtraído e não há contato com a pessoa furtada, o roubo configura-se quando existe contato com a vítima, violência ou ameaça, o que colabora com as narrativas que percebem maior violência nos atos praticados. Evidencia-se também de fato, no meio aberto, $25 \%$ dos atos infracionais corresponderem ao tráfico ou porte de drogas.

Com isso, entende-se que se as narrativas que afirmam o agravamento do perfil vinculado aos atos infracionais cometidos podem ser consideradas relacionadas com atos infracionais com grave ameaça ou violência correspondiam 90\% no ano de 2014; 84\% em 2015; 83,8\% em 2016; 94,5\% em 2017 e 94\% em 2018. Contudo para identificar em que medida o roubo está atrelado ao tráfico de drogas seria necessário uma pesquisa mais detalhada sobre os boletins de ocorrência ou processos desses jovens, bem como dos relatórios que permitem acompanhar o desenvolvimento do adolescente no transcorrer da medida. $\mathrm{O}$ que parece evidente é o contexto de uma violência difusa que, ao mesmo tempo que atinge o contexto de vida desses jovens e os vitimizam, colabora para a prática de ato infracional dos mesmos.

Para Tavares dos Santos (2009, p. 11), dentre as novas questões sociais mundiais, constitui-se uma crise da sociabilidade, chegando no limite, às manifestações de violência, fenômenos que adquirem novos contornos e passando a disseminar-se por toda a sociedade, uma violência difusa". Nesse sentido, a violência difusa também permeia a vida desses jovens em seus territórios de moradia, seja através da repressão policial ou pela pŕopria lógica do tráfico de drogas como uma presença constantes nos bairros onde residem. Para Tavares dos Santos

a violência seria a relação social, caracterizada pelo uso real ou virtual da força ou coerção que impede o reconhecimento do outro - pessoa, classe, gênero ou raça provocando algum tipo de dano, configurando o oposto das possibilidades da sociedade democrática (TAVARES DOS SANTOS, 2009, p. 16).

Conforme abordado por Tavares dos Santos (2009, p. 25) 
$\mathrm{Na}$ condição de efeito dos processos de fragmentação social e de exclusão econômica e social, emergem as práticas de violência como norma social particular de amplos grupos da sociedade, presentes em múltiplas dimensões da violência social e política contemporânea. A interação social passa a ser marcada por estilos violentos de sociabilidade, invertendo as expectativas do processo civilizatório (Elias, 1990, 1993; Bosi, 1994, p. 20).

Conforme abordado pelo autor existem grupos sociais em que a violência é naturalizada e permeia uma série de códigos e linguagens. Com isso, não pretende- se aqui estigmatizar esses jovens como violentos ou discorrer sobre a disposicionalidade violenta de jovens infratores, porque entende-se que os jovens que praticaram a maioria dos atos infracionais (roubo) se diferencia do público alvo da pesquisa de Rolim (2014), jovens envolvidos com a violência extrema. Ao discutir sociologicamente a violência, entende-se a necessidade de compreender como e porque esses jovens em condição de exclusão estão mais expostos a sofrer e praticar atos com violência, considerando que mesmo quando os atos não envolvem um ato contra alguém (como o porte ou o tráfico de drogas) está relacionado com contextos de violência ou criminalidade.

\subsection{Conclusões}

A disucssão em torno dos atos infracionais e da violência no município de Pelotas-RS, buscou elucidar como os agentes institucionais percebem os atos praticados pelos jovens com o que estão relacionados. Por meio da discussão das categorias elencadas a partir dos agentes do campo sócio-jurídico é possível perceber aproximações em determinadas categorias e distanciamentos em outras. De modo geral a configuração da rede tem na enunciação dos seus discursos uma tônica de um "perfil" mais gravoso dos jovens, atos mais violentos, o envolvimento com o tráfico de drogas, a fragilidade dos laços familiares, a evasão escolar, a violação de direitos como características comuns a esse grupo juvenil. No entanto, foi percebido que a mudança não envolve o "perfill" desses jovens, mas sim as ações praticadas por eles, pois ao abordarem quem são os jovens atendidos no sistema socioeducativo as características permanecem as mesmas: jovens em vulnerabilidade, em condição de pobreza ou extrema pobreza, oriundos de famílias com núcleos familiares desagregados ou laçõs familiares frageis, residentes em bairros de periferia etc. Portanto, o que apresenta mudança não é o "perfil do jovem", mas o "perfil da ação" desses sujeitos e nesse sentido, deve-se atentar para não incorporar ao jovens o ato infracional como coisas comuns e inseparáveis.

O envolvimento direto, indireto ou apenas a presença do tráfico de drogas nos territórios habtados por esses sujeitos juvenis foi o elemento mais citado e relacionado a prática de ato infracional e a violência, segundo a percepção dos agentes do campo sócio- 
jurídico, de modo que a ausência de políticas públicas e atuação do Estado na garantia dos direitos das famílias e dos jovens, é ainda mais comprometida com a presença de coletivos criminais no espaço urbano.

A perspectiva relacional e configuracional de Elias (2008), possibilitou a compreensão das dinâmicas da Rede Socioeducação e de que forma o reconhecimento em relação aos jovens e aos atos por eles praticados cofigura a campo-sócio jurídico. Além disso, colabora na compreensão da relação e um contexto de vida onde a violência apresenta-se de modo difuso com as práticas delituosas e as relações com a realidade local.

Este trabalho busca contribuir com a área específica da Sociologia da juventude, a fim de somar outras possibilidades de compreensão sobre o campo sócio-jurídico que faz parte de uma complexa rede de instituições, agentes e campos que compõem o Estado e tomam decisões em relação aos jovens no campo das medidas socioeducativas. O estudo também apresenta uma contribuição, que pode ser importante para o município, tendo em vista que existem poucas produções acadêmicas especificamente nessa área que abordem o campo das medidas socioeducativas na região.

\section{Referências}

ABRAMO, H. W. Considerações sobre a tematização social da juventude no Brasil. Revista Brasileira de Educação. Mai/Jun/Jul/Ago 1997 No5 Set/Out/Nov/Dez 1997 nº 6, p. 25-36. Disponível em: http://www.clam.org.br/bibliotecadigital/uploads/publicacoes/442_1175_abramowendel.pdf. Acesso em: 30 nov. 2018. (artigo em Periódico Digital)

ANDRADE, C. C. Entre gangues e galeras: juventude, violência e sociabilidade na periferia do Distrito Federal. 2007. 276 f. Tese ( Doutorado em Ciências Sociais) - Instituto de Ciências Sociais, Universidade de Brasília, Brasília. 2007. (Tese)

BRASIL. LEI N $N^{\circ}$ 12.594, DE 18 DE JANEIRO DE 2012. Do Sistema Nacional de Atendimento Socioeducativo $\quad$ (sinase). 2012. Disponível $\mathrm{em}$ http://www.planalto.gov.br/CCIVIL_03/_Ato2011-2014/2012/Lei/L12594.htm. Acesso em 27 nov. 2018.

CASTRO, T. B. Notas introdutórias sobre as questões do crime e punição na perspectiva sociológica: uma breve revisão bibliográfica. Revista do Laboratório de Estudos da Violência da UNESP/Marília, p. 37-51, mai. 2018. ISSN 1983-2192. Disponível em: http://webcache.googleusercontent.com/search?q=cache:KjxSpWZHprgJ:www2.marilia.unes p.br/revistas/index.php/levs/article/view/7923/5038+\&cd=1\&hl=pt-BR\&ct=clnk\&gl=br. Acesso em: 24 jun. 2018. (Arttigo em Periódico Digital)

DOUTOR, C. Um olhar sociológico sobre os conceitos de juventude e de práticas culturais: Perspetivas e reflexões. Ultima década., v. 24, n. 45, p. 159-174, dez. 2016. ISSN 0718-2236. 
Disponível em: $\quad$ https://scielo.conicyt.cl/scielo.php?script=sci_arttext\&pid=S071822362016000200009\&lng=es\&nrm=iso. Acesso em: em 24 dez. 2018. (Artigo em Periódico Digital)

ELIAS, N. Introdução à Sociologia. Lisboa: Edições 70, 2008. 208 p. (Obra Completa)

ELIAS, N. Conceitos sociológicos fundamentais. In: Escritos \& Ensaios. NEIBURG, Federico; WAIZBORT, Leopoldo. (Org.). Rio de Janeiro: Zahar, 2006, p. 21-33. (Capítulo de Livro)

GROPPO, A. Teorias críticas da juventude: geração, moratória social e subculturas juvenis. Em Tese, Florianópolis, v. 12, n. 1, p. 30, jan./jul., 2015. SSN: 1806-5023. Disponível em: https://periodicos.ufsc.br/index.php/emtese/article/view/1806-5023.2015v12n1p4/29763.

Acesso em: 26 nov 2018. (Artigo em Periódico Digital)

(1982). O problema sociológico das gerações [tradução: Cláudio Marcondes], In Marialice M. Foracchi (org), Karl Mannheim: Sociologia, São Paulo, Ática, pp. 67-95.

MARINHO, F. C. Mudanças, resistências e composições na justiça juvenil [manuscrito]: abordagem comparativa entre Brasil e França. 2012. 326 f. Tese (Doutorado em Sociologia) - Faculdade de Filosofia e Ciências Humanas, Universidade Federal de Minas Gerais, Minas Gerais. 2016. (Tese)

NOVAES, R. VANNUCHI, P. Juventude e Sociedade - Trabalho , Educação , Cultura E Participação. Fundação Perseu Abramo, 2007. 304 p.

PAIS, J. M. Culturas Juvenis. Lisboa: Imprensa Nacional - Casa da Moeda, 2003. 352 p. (Obra Completa)

PELOTAS, Secretaria Municipal de Assistência Social. Plano Municipal de Atendimento Socioeducativo do Município de Pelotas, Rio Grande do Sul. Vigência 2014 a 2023. Pelotas Dezembro de 2014. Revisado e Reformulado em Novembro de 2018.

ROLIN, M. A formação de jovens violentos: Estudo sobre a etiologia da violência extrema. Curitiba: Appris, 2016. 287 p. (Obra Completa)

SPOSITO, M. (2009). O Estado da Arte sobre juventude na pós-graduação brasileira: educação, ciências sociais e serviço social (1999-2006), Belo Horizonte, MG. Argvmentvm, 2009. $278 \mathrm{p}$.

TAVARES, B. Sociologia da Juventude: da juventude desviante ao protagonismo jovem da Unesco. Soc. e Cult., Goiânia, v. 15, n. 1, p. 181-191, jan./jun. 2012. DOI: 10.5216. Disponível em: https://revistas.ufg.br/fchf/article/view/20683/12335. Acesso em: 22jun. 2018. (Artigo em Periódico Digital)

TAVARES DOS SANTOS. J.V (2009.). Violências e conflitualidades. Porto Alegre: Tomo Editorial, 2009. (Série Sociologoa das Conflitualidades, 3). 176 p. (Obra completa) 